\title{
A Multi-Sectional Arc Eliminator for Protection of Low Voltage Electrical Equipment
}

\author{
Karol Nowak *, Jerzy Janiszewski and Grzegorz Dombek \\ Institute of Electric Power Engineering, Poznan University of Technology, Piotrowo 3A, 60-965 Poznan, Poland; \\ jerzy.janiszewski@put.poznan.pl (J.J.); grzegorz.dombek@put.poznan.pl (G.D.) \\ * Correspondence: karol.nowak@put.poznan.pl; Tel.: +48-61-665-2584
}

Received: 11 December 2019; Accepted: 28 January 2020; Published: 30 January 2020

check for updates

\begin{abstract}
The paper presents a system of two oppositely connected multi-sectional thyristor branches. The system works as a multi-sectional arc eliminator (MSAE), protecting low-voltage electrical apparatus against the effects of an arcing fault. MSAE is designed to serve as a device cooperating with protected and secured electrical equipment. The use of thyristors in the proposed solution allows to obtain a high speed of operation, while multi-sectional thyristor branches significantly increase the permissible current load of the arc eliminator. A test circuit was designed and made to test the performance effectiveness of the multi-sectional thyristor arc eliminator. A number of tests were carried out with variable current values in the arc branch, taking into account the influence of thyristor conduction voltage and different thyristor gate release times. It was found that the multi-section thyristor arc eliminator system effectively protects devices powered from low voltage power network against the effects of interference or arc fault.
\end{abstract}

Keywords: arc eliminator; arc protection; current bypass

\section{Introduction}

Short circuits and accompanying electric arcs are the most difficult operating conditions in power circuits. Limiting the negative effects of these factors is an important element in improving the operational safety of power systems. One way to reduce these effects is by bypassing the affected circuit. For this purpose, contact jacks with relatively long switching times [1] and limited contact capacity are usually used. The long delay in tripping the bypass circuit is accompanied by a significant emission of heat energy from the arc burning in the affected circuit and its power supply current circuits.

Interference current shunting devices and systems are used in many protective applications. They can be found, for example, in motor-drive systems exposed to arcuate interference [2], reactive power compensation devices [3], photovoltaic panel protection systems [4], hybrid circuit breakers [5,6], electric vehicle protection systems [7], and circuit breaker systems used to prevent electric fires [8]. Bypassing circuits are built based on Thomson's electromagnetic coil [9,10], spring mechanisms accelerated by electromagnetic systems [11,12], circuits interrupted by an explosive charge [13] or containing compressed gas [14], and also on semiconductor devices [15,16].

One of the most common types of electrical short circuit is arc fault. Most often, an arc occurs as a result of improper operation of distribution devices, bad design solutions or environmental conditions in which electric devices work $[17,18]$. Among the many available methods for eliminating the effects of arc faults, two groups are interesting $[19,20]$ :

- limitation of the current value by adding supplementary (higher) impedance to the power supply circuit,

- limitation of the arcing discharge duration. 
The preferred solution from the power supply point of view is the arc time limitation method [21]. This effect can be achieved by bypassing the damaged circuit with semiconductor short circuiting elements. The use of a thyristor arc eliminator causes a virtually instantaneous elimination of the arc fault in the affected circuit $[15,16]$. An additional advantage of the arc eliminator (AE) is arc-free short-circuit current commutation in AE branches and a shorter duration of thermal effects in the protected circuit.

Little research has been done on the use of semiconductor components as short-circuit switches or arc eliminators $[3,5,16,22,23]$. The available works deal with currents ranging from hundreds to several thousand amperes. Short-circuit currents expected in many power circuits today exceed tens of thousands of amperes and no commercial thyristors with this current capacity have not been available so far. The thyristor multi-sectional arc eliminator (MSAE) presented in this paper is a way to solve this problem. A number of experiments described in publications $[15,16]$ confirm the justifiability of using two counter-connected thyristors as an AE. This current research has been carried out for a multi-sectional semiconductor module, which is an improved version of the AE presented in paper [15]. This solution significantly extends the usability of the version presented in [15]. Ultimately, the multi-sectional semiconductor module can work in the hybrid short-circuiting switch, a subject of an original solution submitted in a patent application [24,25].

The use of two oppositely connected thyristors as an arc eliminator can be limited by the permissible forward current for each thyristor $[26,27]$. AE semiconductor elements must be selected in such a way as to allow the flow of the interference current as long as it is required to eliminate the interference or trip the master circuit breaker. It makes it more difficult to choose semiconductor elements and increases of the construction costs of an arc protection device. The current-carrying capacity of an arc eliminator can be increased through parallel connection of semiconductor components. However, this connection arrangement has several disadvantages. It requires careful selection of semiconductors, assurance of simultaneous control of all gates and alignment of current values in thyristor branches.

The purpose of this work is to solve the issue of increasing the current-carrying capacity of the semiconductor arc eliminator while maintaining its operational efficiency, i.e., arc elimination and the shortening of current flow time in the protected circuit. Unlike in works [15,16], an AE study based on multi-sectional thyristor shunt branches was performed. The system allows for a sequential (in each half-wave) takeover of the disturbing current by individual bypass sections, which enables the shortening of the time of current flow in subsequent branches of the device, until the electric arc goes out or the contacts of the main switch open. Consequently, an increase in short-term current carrying capacity is achieved in individual semiconductor branches of the arc eliminator as well as an increase in its total switching capability.

\section{Methodology and Research Object}

\subsection{Methodology}

MSAE tests were performed in a circuit fed from a 400/230 V AC power network with a maximum short-circuit current $I_{R M S}=2500 \mathrm{~A}$. The arc current was regulated by means of an additional series impedance. Current and voltage waveforms were recorded using the Voltcraft 1084E and Voltcraft 1084F oscilloscopes (Conrad Electronic International GmbH \& Co KG, Wels, Austria). The tests were performed in a system with arc simulation (using an arc detector stimulated by an LED light pulse) and in a real system, where the detector was stimulated by the arcing light. Arcs were initiated with the use of a fuse element in the arc generator system presented in [15].

The MSAE design uses two- and three-section thyristor shunt branches for each half of the flowing current. In thyristor branches, semiconductors characterized by different conduction voltages were used. For the triggering of semiconductor elements, a microprocessor controller was used which allowed any selection of initiation and conduction times for individual thyristor branches. 


\subsection{Multi-sectional Thyristhor Arc Fault Eliminator}

The thyristor arc eliminator is a protective device connected in parallel to the load. A substitute diagram of the low-voltage power grid is shown in Figure 1.

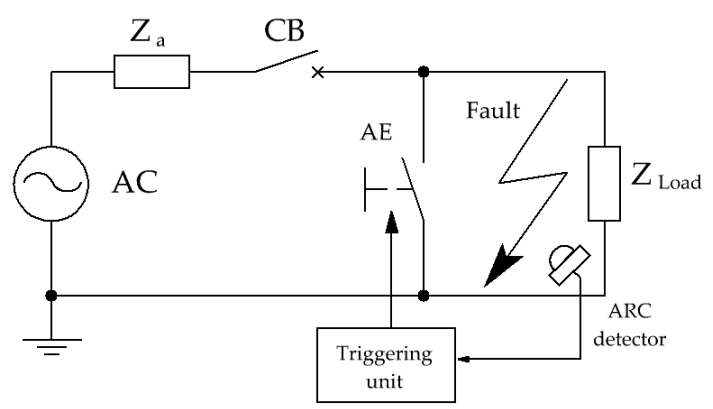

Figure 1. The idea of using the arc eliminator to protect low-voltage network equipment; $\mathrm{CB}$ - circuit breaker, $Z_{\text {Load }}$-load $(\Omega)$, AE—arc eliminator, $Z_{a}$-impedance of the power line $(\Omega)$.

If an electric arc is ignited during current flow in the AE-protected circuit will be retained by the activation of the arc detector causes a practically immediate activation of $\mathrm{AE}$ and the commutation of disturbance current flow in the bypass branch (AE) until the main switch (CB) is activated or the electric arc is switched off. The voltage of the conductive eliminator is significantly lower than that of the arc, so the arc is extinguished in a short time without causing the main electrical circuit protection to turn off (provided that the AE is switched off). A source of electric arc (arc generator) was used in the research, the structure and essence of which is presented in paper [15].

Having conducted a series of studies the authors found that a semiconductor system of two oppositely connected semiconductor elements allowed very fast bypassing of an electric circuit affected by arcuate interference, aimed at creating an alternative, privileged path for current flow. Such $\mathrm{AE}$ operation forces the immediate elimination of the resulting arc fault, and the shortening of arc fault duration simultaneously reduces the values of fault current and arc energy.

In order not to damage the thyristors during the flow of interference current, it is necessary to select their limit parameters properly, particularly the absolute maximum surge current $I_{T s m}$, whose catalog value is given, as a rule, for the flow time of $10 \mathrm{~ms}$. In the case of parameters defined as unique, the condition is that the value cannot be repeated until the thermal effects of its previous occurrence have ceased. Consequently, in the event of subsequent ignition of the arc in successive half-waves of current flow, in principle, the previously used thyristor cannot be turned on to eliminate the interference. The thermal effects of successive semi-waves of the flowing current can lead to damage to the semiconductor. A measure of the sensitivity of a semiconductor valve to its short circuit heat can be its Joule integral. The $I^{2} t$ value is called the overload parameter of the semiconductor element [28].

One of the solutions to the above problem is the use a thyristor with much higher parameters of current overload capacity without changing its properties in a specified time. Unfortunately, this is linked to a significant increase in the price of the arc eliminator. By analyzing the prices of semiconductors [29] as a function of the maximum surge current, it can be seen that the increase follows an exponential curve.

It may be problematic when the load current is higher than the limit maximum surge current of a single thyristor. The solution to this issue is to connect thyristors in parallel. When two or more thyristors are connected in parallel, the following conditions must be met:

- all thyristors should belong to the same group and have the same forward voltage,

- the highest value of the load current flowing through a group of thyristors connected in parallel should be less than the sum of the limit currents of the individual thyristors,

- a simultaneous switching-on time of all thyristors should be ensured by the use of a quick trigger unit which sends, at one moment, appropriately formed pulses to each thyristor gate, 
- equalization of current distribution in individual branches.

Such a connection of semiconductor elements is burdened with the dispersion of voltage-current characteristics in the conduction state and a need to select semiconductor elements. Incorrect selection results in an uneven distribution of currents in the steady state in individual branches. In order to obtain a sufficiently uniform current distribution, thyristors are selected to match the voltage-current characteristics in the conduction state. It is usually sufficient to match the thyristor forward voltage value at the limiting current [30]. The dispersion of thyristor characteristics may not be the main cause of the uneven current distribution in a parallel connection. Current distribution is significantly affected by impedance distribution in individual branches and elements (connections, wires), usually connected in series with each thyristor.

In the case of excessive irregularity of current distribution (in parallel thyristor branches), it is necessary to use equalizing elements. This solution gives good results when working in steady states, however, it reduces the efficiency of the whole system and requires the use of equalization impedance with appropriate current-carrying capacity, at least equal to the thyristor used in series. Uneven current distribution is also associated with unfavorable transition states in thyristors, especially with the switching state [30]. The thyristor with the shortest switching time initially conducts the total load current of the system.

The solution to the problem of increasing the current load capacity of the arc eliminator while maintaining its effectiveness described in [15] is to use a multi-sectional bypass branch made of semiconductor elements. Figure 2 shows a diagram of a multi-section thyristor electric arc eliminator in a thyristor design.

The use of a multi-sectional branch bypassing the electrical interference allows for sequential take-up of short circuit current by individual bypass tracks, which shortens the current flow time in subsequent sections of the device until the electric arc is switched off or the contacts of the master switch are open. Consequently, an increase is achieved in current carrying capacity in individual semiconductor branches of the arc eliminator as well as a growth in its total current load capacity.

The schematic diagram in Figure 2 shows the configuration of a Multi-Sectional Electric Arc Eliminator (MSAE) for direct and alternating current. Thyristor or diode-thyristor blocks of bypass cascades are turned on, respectively, for positive or negative polarity (half sine wave) of the flowing current. To facilitate the description of the arc eliminator, the following abbreviations have been adopted:

- $\mathrm{MB}$ - semiconductor bypass module for the positive half-wave of the flowing current, which consists of semiconductors $1,2, \ldots, n$,

- $\mathrm{MB}^{\prime}$ - semiconductor bypass module for the negative half-wave of the flowing current, which consists of semiconductors $1^{\prime}, 2^{\prime}, \ldots, n^{\prime}$.

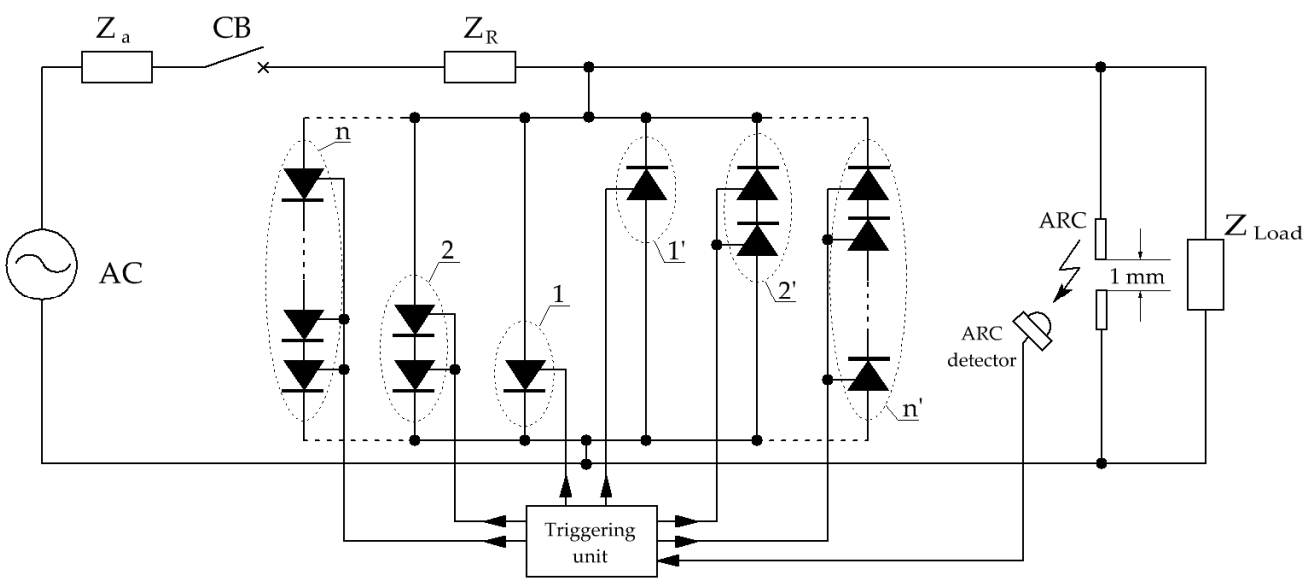

Figure 2. Schematic diagram of the Multi-Section Arc Eliminator MSAE made by the thyristor. 
For each half-wave of the sinusoid supplying the presented system, it is a set of the ARC detector (common for both current polarizations) and cascading semiconductor bypassing tracks (branches) $1,2, \ldots, n$ or respectively $1^{\prime}, 2^{\prime}, \ldots, n^{\prime}$. Individual bypassing branches are composed of an increasing number of serially connected semiconductor valves, of which at least one is a thyristor in each branch. From the operational perspective, it is beneficial for the system to contain only thyristor shunt branches (Figure 2), but it may be economically advantageous to use a diode-and-thyristor design. Along with arc flash detection, the activation of the arc eliminator takes place by controlling the thyristors in the last bypassing branch ( $n$-for positive polarization or $n^{\prime}-$ for negative polarization respectively) and then in subsequent parallel branches $(n-1),(n-2)$, etc., or respectively $\left(n^{\prime}-1\right),\left(n^{\prime}-2\right)$, etc. The condition for taking over current conduction by successive branches of the semiconductor shunt $n,(n-1) \ldots 2$, 1 of the MB bypass module (or $n^{\prime},\left(n^{\prime}-1\right) \ldots 2^{\prime}, 1^{\prime}$ for $\mathrm{MB}^{\prime}$ ) is proper control of thyristor gates. The task of serial thyristors and diodes in higher-order semiconductor branches is to maintain in their conduction state a voltage drop sufficient to switch on the elements of the lower-order sections. The whole procedure ensures that the fault current or arc current in the semiconductor circuits is taken over for the time that is necessary to extinguish the resulting electric arc or open the contacts of the main switch. In this way, it achieves virtually instantaneous operation of the AE and gradually relieves its semiconductor elements.

Thanks to the application of the solution according to Figure 2, the following technical and utility effects have been achieved:

- increased current load capacity of the arc eliminator,

- practically immediate elimination of the arc fault in the damaged circuit,

- extended time available to open the main switch contacts in the case of re-ignition of the arc in subsequent half-waves of the flowing arc current,

- shorter time of impact of thermal effects in the circuit to be protected,

- reduced electrodynamic effects,

- $\quad$ ability to optimize the thermal load of individual semiconductor branches,

- possible cooperation with arc protection devices available on the market,

- reduced costs of implementation in diode-thyristor solutions.

Figure 3 shows part of a test circuit of a multi-sectional arc eliminator with marked measurement signal registration points. The supply voltage is registered in relation to the protective conductor PE. The arc voltage was registered with the DP-50 voltage differential probe (Pintek Electronics Co. Ltd., Shulin, New Taipei City, Taiwan). The differential probe terminals are located as close as possible to the electrodes of the arc generator. The value of the current in the branches of the $\mathrm{AE}$ and the load, as well as the current taken from the source were recorded using current probes PAC22 (Chauvin Arnoux, Paris, France). 


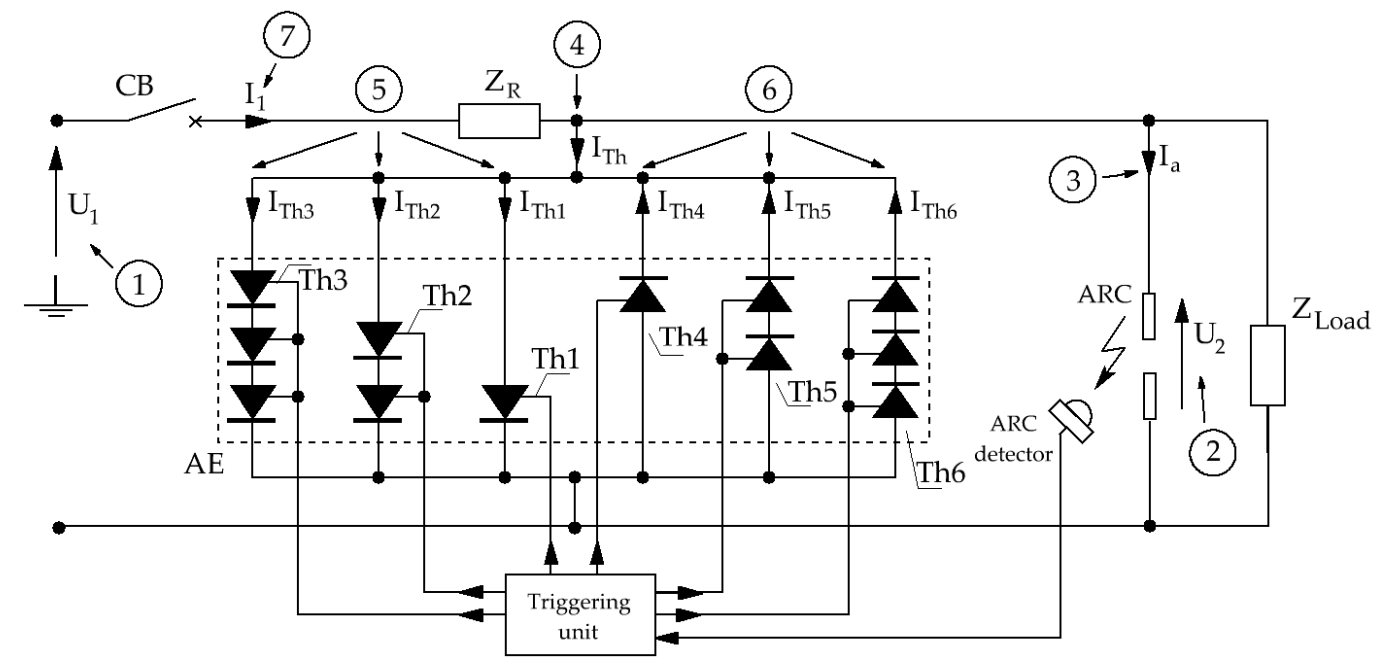

Figure 3. Part of the arc eliminator test circuit MSAE with marked measurement points: 1—supply voltage $\left(U_{1}\right), 2$-voltage on the electrodes of the arc source $\left(U_{2}\right), 3$-current in the branch of the arc source $(I a), 4$-current in the thyristor branch $\left(I_{T h}\right), 5$-current for the positive half-wave of the flowing current MB $\left(I_{T h 1}, I_{T h 2}, I_{T h 3}\right), 6$ - current for the negative half-wave of the flowing current MB' $\left(I_{T h 4}, I_{T h 5}\right.$, $\left.I_{\text {Th6 }}\right), 7$ - power source current $\left(I_{1}\right)$.

\section{Thyristor Triggering Procedure}

The exemplary solution of the current circuit of a multi-sectional arc eliminator shown in Figure 3 contains two $\mathrm{MB}$ and $\mathrm{MB}^{\prime}$ modules, each containing three semiconductor branches bypassing a place affected by arc disturbance (ARC). The individual components of the semiconductor cascade are switched on in a sequence of $\mathrm{T}_{\mathrm{h} 3} \rightarrow \mathrm{T}_{\mathrm{h} 2} \rightarrow \mathrm{T}_{\mathrm{h} 1}$, followed by $\mathrm{T}_{\mathrm{h} 6} \rightarrow \mathrm{T}_{\mathrm{h} 5} \rightarrow \mathrm{T}_{\mathrm{h} 4}$, when the detected initial fault current polarity is positive or, when the detected current has negative polarity it runs in the order of $\mathrm{T}_{\mathrm{h} 6} \rightarrow \mathrm{T}_{\mathrm{h} 5} \rightarrow \mathrm{T}_{\mathrm{h} 4}$, and then $\mathrm{T}_{\mathrm{h} 3} \rightarrow \mathrm{T}_{\mathrm{h} 2} \rightarrow \mathrm{T}_{\mathrm{h} 1}$. Subsequent switching on of thyristor branches in each of the $\mathrm{MB}$ and $\mathrm{MB}^{\prime}$ modules run in accordance with the decreasing voltage drop in the individual bypass sections. Sequential closing of semiconductor circuits allows the fault current to be taken over by individual branches of the short-circuiting switch in the way shown as an example in Figure 4.The sequence of taking over the current by successive branches of the arc eliminator shown in Figure 4 is connected with the appropriate triggering of subsequent thyristors. The control unit for thyristor modules ( $\mathrm{MB}$ and $\left.\mathrm{MB}^{\prime}\right)$ consists of systems enabling the following:

- generation of gating pulses,

- appropriate time modulation, synchronization and distribution of these pulses,

- input control signal conversion and adaptation (regardless of signal source),

- operation of the system of interlocks and safeguards affecting the triggering pulses,

- elimination or limitation of external influences such as: temperature, voltage changes, power supply, interference, etc.

The requirements for thyristor triggering systems include [31]:

- $\quad$ ensuring an appropriate value of the tripping current and gate voltage. These requirements also include the optimization of rise steepness and trigger pulse duration,

- minimizing the trigger delay in relation to the moment the signal triggering the trigger pulse occurs,

- ensuring the maximum operational reliability,

- galvanic separation of output circuits supplying the gates of individual thyristors.

The above requirements are met by the thyristor microprocessor controller described in detail in [32]. The device was expanded with the ability to independently control six thyristor sections 
$\left(T_{h 1}, T_{h 2}, T_{h 3}, T_{h 4}, T_{h 5}, T_{h 5}\right)$ and an external trigger input, which, based on the signal from the arc detector, initiates the process of controlling thyristor sections. The microprocessor thyristor controller can be used with commercial arc interference detectors. In the experimental tests presented below, the controller was activated from a simple arc flash detector based only on light detection of a burning arc. The occurrence of arc interference in the initial or final phase of the supply voltage half-wave has no effect on the operation and control of the appropriate section of arc eliminator thyristors.

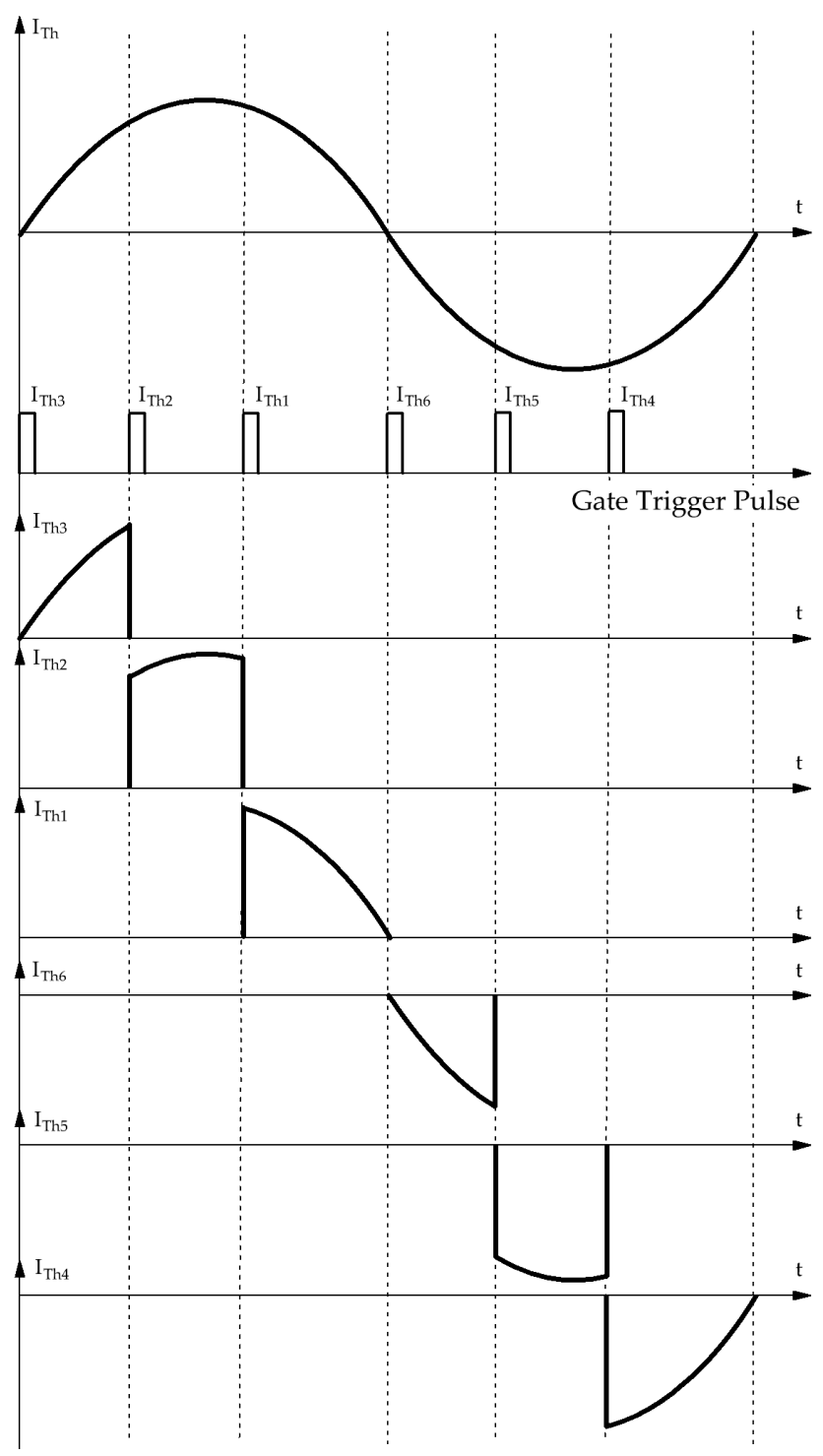

Figure 4. An example of sequential taking over of current by shunting paths in the order in which thyristors are triggered $T_{h 1}, T_{h 2}, T_{h 3}, T_{h 4}, T_{h 5}, T_{h 6}$.

Figure 5 shows the recorded gating pulses of the individual thyristor sections. In each of the four presented oscillograms, supply voltage $U_{1}$ and gate voltage impulses triggering the thyristors $T_{h 1}, T_{h 2}$, $T_{h 3}, T_{h 4}, T_{h 5}$ and $T_{h 6}$ were recorded. For the positive half-wave, the supply voltages are sequentially $T_{h 3}, T_{h 2}$, and $T_{h 1}$, and for the negative half-wave the supply voltages are $T_{h 6}, T_{h 5}$, and $T_{h 4}$. Figure $5 a$ shows the arc ignition moment during a negative supply voltage semi-wave and Figure $5 \mathrm{~b}$ shows the arc ignition moment during a positive supply voltage semi-wave. The test circuit was designed in such a way as to create favorable conditions for subsequent arc ignitions. Detection of the electric arc and identification of the direction of the disturbed current flow causes the generation of the control pulse 
and the sequential triggering of the appropriate group of thyristors. Successive electric arc flashes trigger the detection system and cause subsequent triggering of the thyristor groups.

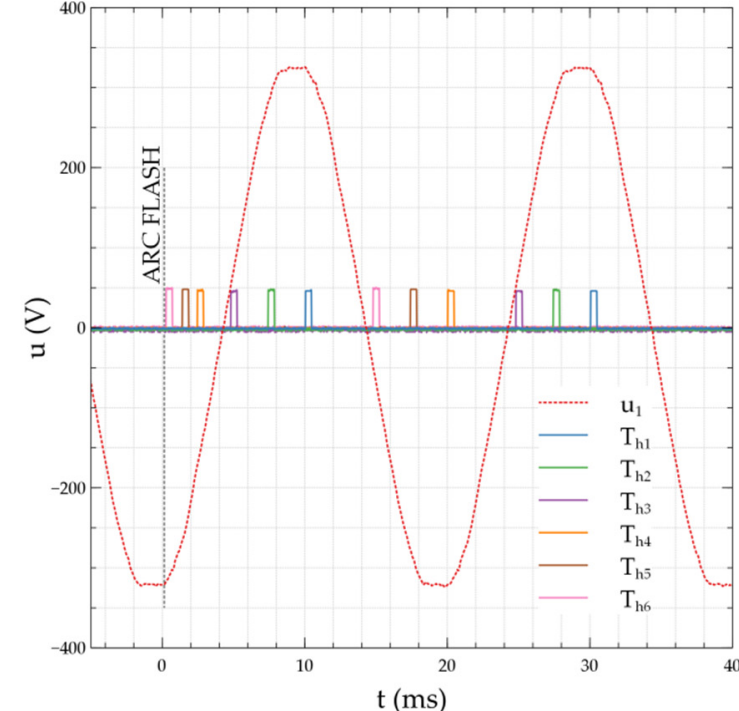

(a)

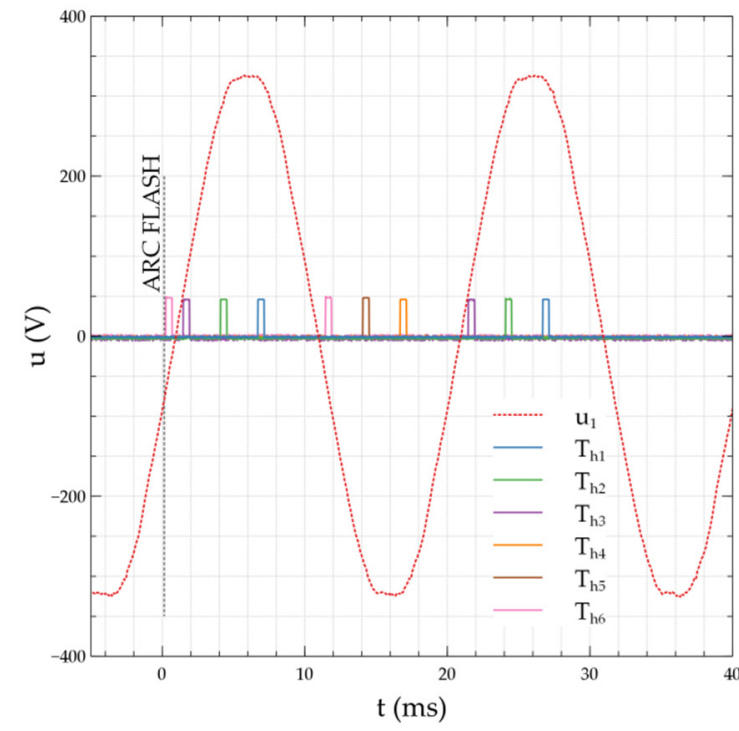

(c)

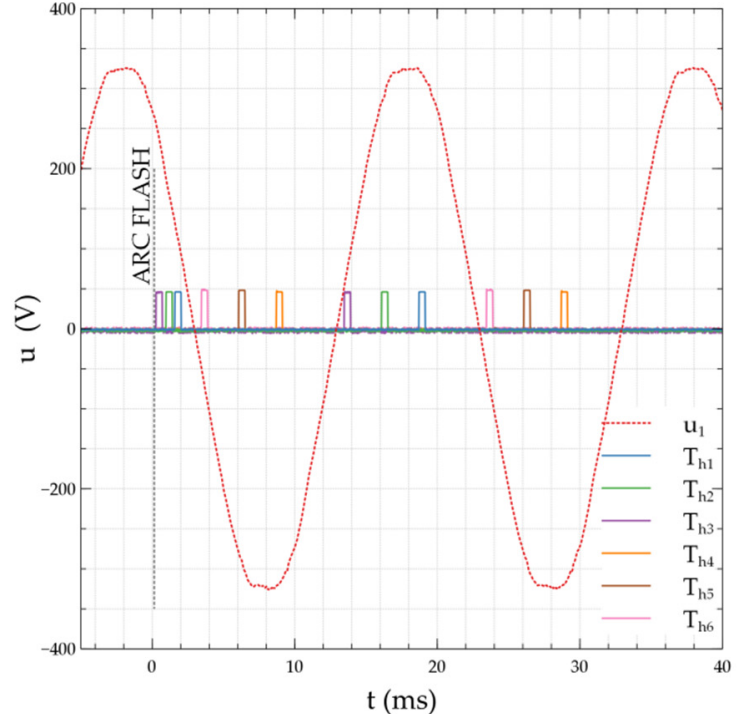

(b)

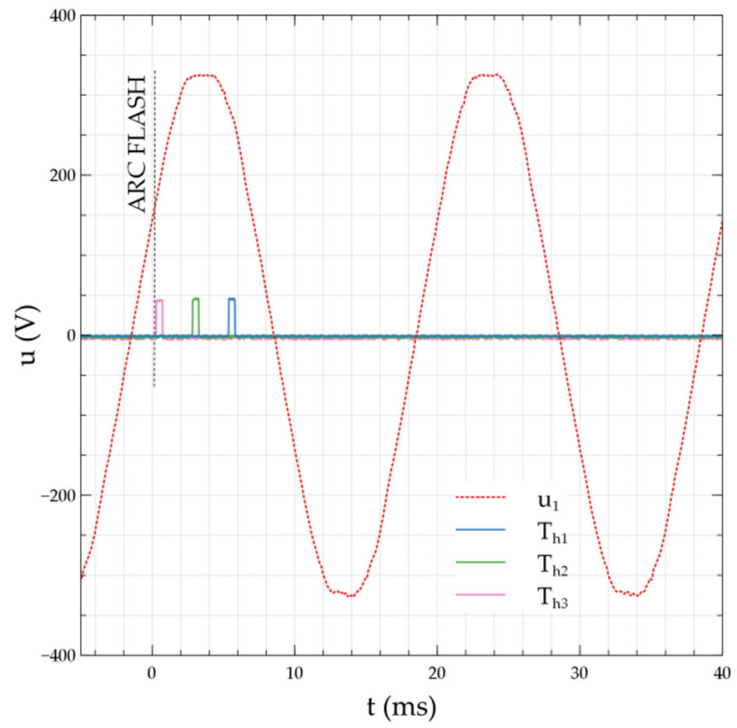

(d)

Figure 5. Pulses triggering thyristors $T_{h 1}, T_{h 2}, T_{h 3}, T_{h 4}, T_{h 5}$, and $T_{h 6}$ in the MSAE control system in relation to supply voltage $u_{1}$ : (a) arc flash in the negative voltage half-wave; (b) arc flash in the positive voltage half-wave; (c) arc flash at the end of the positive half-wave voltage, the algorithm generates only one triggering pulse; (d) the arc extinguishes in the first half wave of voltage.

In the oscillograms in Figure 5a, and Figure 5b, it can be clearly seen that only one group of thyristors is triggered for a given supply voltage half-wave. Figure $5 c$ shows the moment of appearance of an electric arc flash in the final part of the supply voltage half-wave. Flash detection takes place about $0.8 \mathrm{~ms}$ before the time of voltage transition through zero, which determines the natural extinguishing of the electric arc in resistive circuits typical of low-voltage electrical installations. In such a short time that remains until $u_{1}(t)=0 \mathrm{~V}$ only one of the thyristors is triggered.

At the moment of a programmed arc flash detection, the microprocessor controller calculates the $t_{p}$ time left before the half-wave current passes through zero. Depending on the remaining time, one, two or three thyristor sections are triggered: 
For the three bypass branch sections, the following trigger times were determined:

- the flash detection moment is the beginning of the countdown of time $t_{p}$ remaining to the end of the half-wave current,

- when the flash is detected, the section with the highest number of thyristors is triggered,

- after, for example, $30 \%$ of $t_{p}$ time, the lower order semiconductor section is triggered,

- after, for example, $60 \%$ of $t_{p}$ time, the lowest order semiconductor section is triggered.

For the $t_{p}$ time of $1 \mathrm{~ms}<t_{p}<2 \mathrm{~ms}$, two thyristor sections of the highest order are triggered with a conductive time division of $50 \%$ of the $t_{p}$. For times $t_{p}<1 \mathrm{~ms}$, one top-level section is triggered.

The microprocessor algorithm is the decision system in this case. In the applied controller, there is a possibility to create any algorithms in making decisions about the optimal load on the thyristor section. This configuration freedom allows to change:

- the duration of the trigger pulse,

- the time between successive trigger pulses,

- decisions on the number of triggered sections in a given half-wave of current flow.

The oscillogram in Figure 5d was recorded in a system with an arc extinguishing itself after a time of $T_{a}<10 \mathrm{~ms}$. $T_{a}$ is the duration of the electric arc. The trigger of the appropriate group of thyristors that can conduct current, occurs when the electric arc is detected. Because the electric arc appeared in the positive half-wave of the flowing current, $\mathrm{T}_{\mathrm{h} 3}, \mathrm{~T}_{\mathrm{h} 2}$ and $\mathrm{T}_{\mathrm{h} 1}$ thyristors were triggered. The arc is extinguished during the first half-wave of power supply voltage, so there are no further gating impulses.

\section{Investigations of Currents and Voltages in the Multi-Sectional Arc Eliminator System}

The schematic diagrams in Figures 6 and 7 show the solution of the arc eliminator in the following systems:

- two-sectional-containing two branches bypassing the arc fault: $\mathrm{T}_{\mathrm{h} 3}$ and $\mathrm{T}_{\mathrm{h} 1}$ for the positive half-wave supply voltage and the corresponding $\mathrm{T}_{\mathrm{h} 6}$ and $\mathrm{T}_{\mathrm{h} 4}$ for the negative. Higher-order sections $\left(\mathrm{T}_{\mathrm{h} 3}\right.$ and $\left.\mathrm{T}_{\mathrm{h} 4}\right)$ are made of more semiconductor components than lower-order sections $\left(\mathrm{T}_{\mathrm{h} 1}\right.$ and $\left.\mathrm{T}_{\mathrm{h} 4}\right)$,

- three-sectional-containing two branches bypassing the arc fault: $\mathrm{T}_{\mathrm{h} 3}, \mathrm{~T}_{\mathrm{h} 2}$ and $\mathrm{T}_{\mathrm{h} 1}$ for the positive half-wave supply voltage and corresponding $T_{h 6}, T_{h 5}$ and $T_{h 4}$ for the negative. Each of the lower-order sections contains in its connection one semiconductor element less than the preceding higher-order section.

Due to the short circuit conditions at the measuring point, the value of the $I_{T h}$ was limited by means of additional impedance $Z_{R}$ to the maximum value $I_{\text {Thmax }}$. The circuit has a resistive character, and the insignificant inductance included in the impedance results from the parameters of the power supply circuit and the connections inside the AE. The preliminary test in the systems shown in Figures 6 and 7 was carried out at triggering the $T_{h 3}$ thyristor sections at the moment of passing the voltage half-wave through zero. They were made in a circuit with a simulation of arc by means of an LED diode turned on at the moment $u_{1}(t)=0 \mathrm{~V}$. This method of control allows to register the possibility of dividing the full half-wave of the flowing current into fragments and show conduction through individual thyristor sections.

Current flows in the solutions presented are shown in Figures 8 and 9. Figure 8 shows the current and voltage waveforms in the two-section arc eliminator circuit (Figure 6), recorded in the duration of the interference for two periods of the supply voltage. The first $\mathrm{T}_{\mathrm{h} 3}$ thyristor section is triggered when $u_{1}(t)=0 \mathrm{~V}$ (about $0.137 \mathrm{~ms}$ ). The activated thyristors allow the flow of $I_{T h 3}$ current. The higher number of series semiconductors in the higher order bypass branch $\mathrm{T}_{\mathrm{h} 3}$ in the conduction state causes the voltage to drop sufficiently enough to trigger the elements of the lower order section Th1. After 
the period resulting from the division of the voltage half-wave duration into two (not necessarily equal) parts (two semiconductor sections) the impulse triggering the Th1 lower order section is given. Triggering the Th1 branch causes the $I_{T h 1}$ current to flow. A smaller number of working semiconductors in the lower order bypass branch $\mathrm{T}_{\mathrm{h} 1}$ lowers the voltage drop, making it impossible to maintain the conduction in elements of the higher section $\mathrm{T}_{\mathrm{h} 3}$. The group of thyristors from the $\mathrm{T}_{\mathrm{h} 3}$ section ceases to conduct $I_{T h 3}$ current, which results in the complete taking over of the conductivity by the $\mathrm{T}_{\mathrm{h} 1}$ section. The current $I_{T h}$ registered with a current probe and shown in Figure 8 is the sum of the currents flowing in the subsequent sections of the arc eliminator. Continuity of the $I_{T h}$ current flow indicates the state of activity of the arc eliminator.

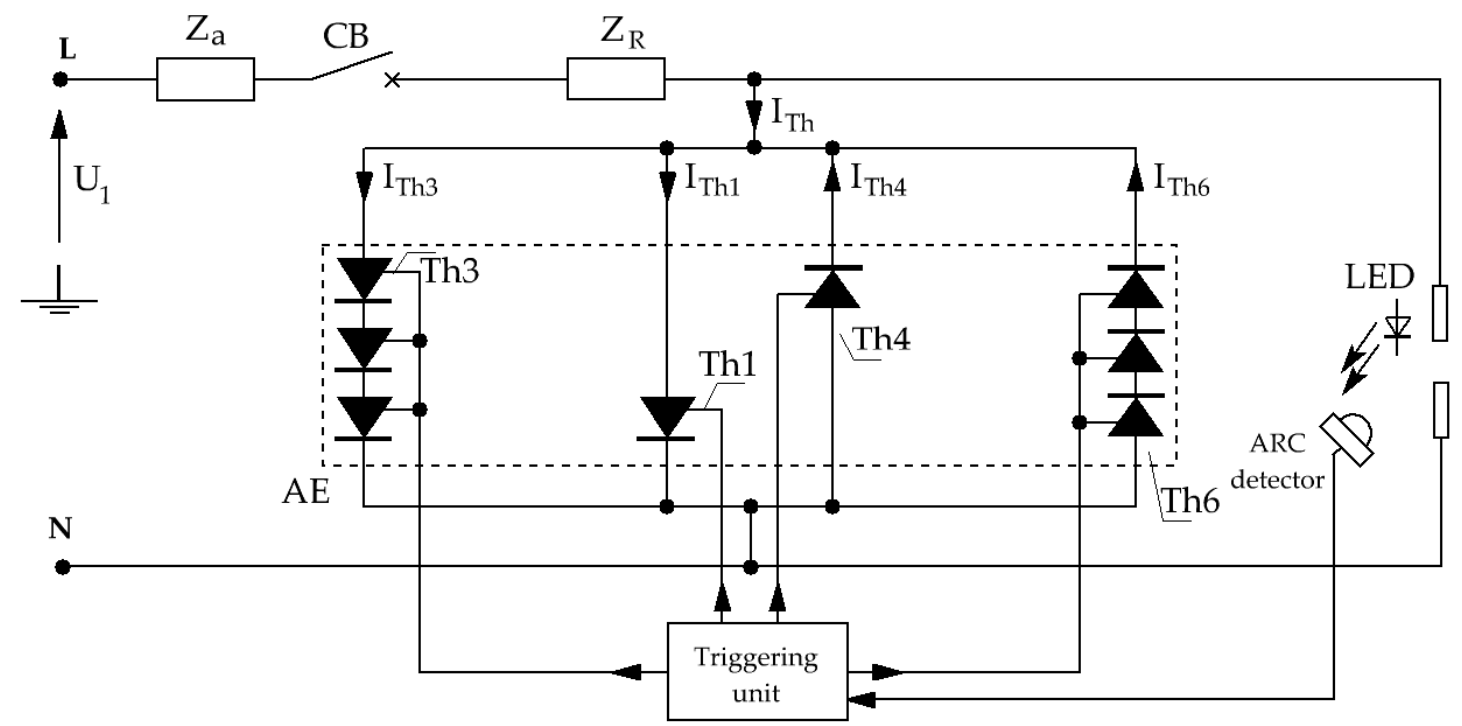

Figure 6. Schematic diagram of the test circuit in a two-sectional MSAE system.

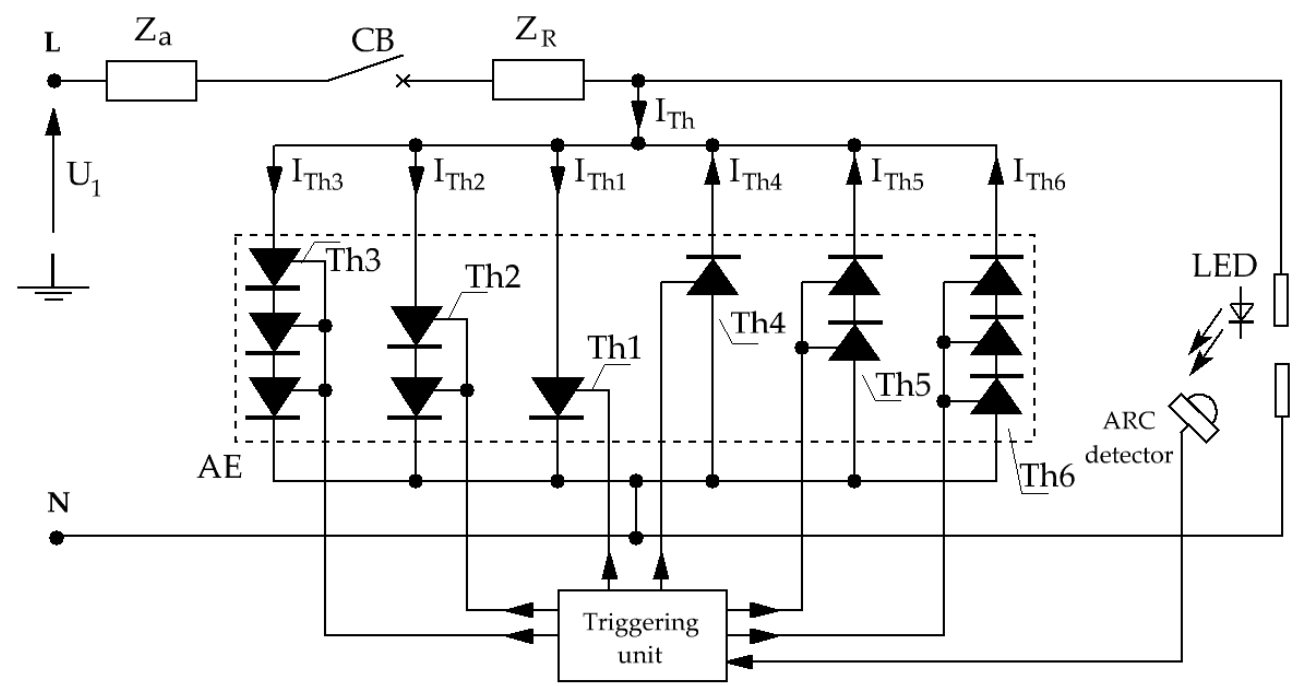

Figure 7. Schematic diagram of the test circuit in a three-sectional MSAE system.

Figure 9 shows the current and voltage waveforms in the three-sectional arc eliminator circuit shown in Figure 7. The recorded waveforms are limited to two periods of supply voltage. At the moment when the supply voltage $u_{1}(t)=0 \mathrm{~V}$ (about $0.138 \mathrm{~ms}$ ) the first $\mathrm{T}_{\mathrm{h} 3}$ thyristor section is triggered. Current $I_{T h 3}$ flows through the controlled thyristors. A larger number of serial semiconductor elements in the higher order bypass branch $\mathrm{T}_{\mathrm{h} 3}$ in the conduction state, maintains a sufficient voltage drop to trigger the elements of the lower order $\mathrm{T}_{\mathrm{h} 2}$ section, built of a smaller number of in series connected semiconductor elements. 


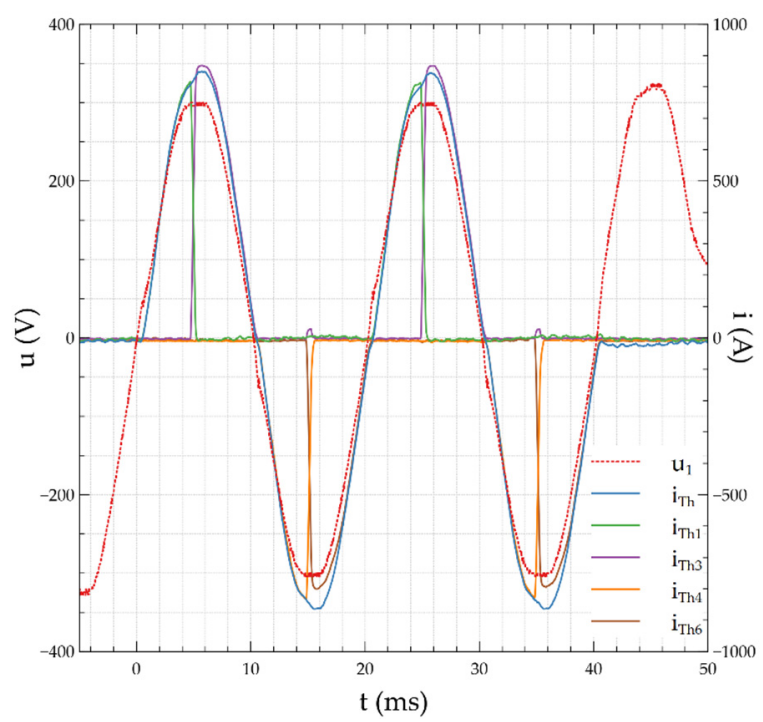

Figure 8. Current and voltage waveforms in a two-sectional MSAE system.

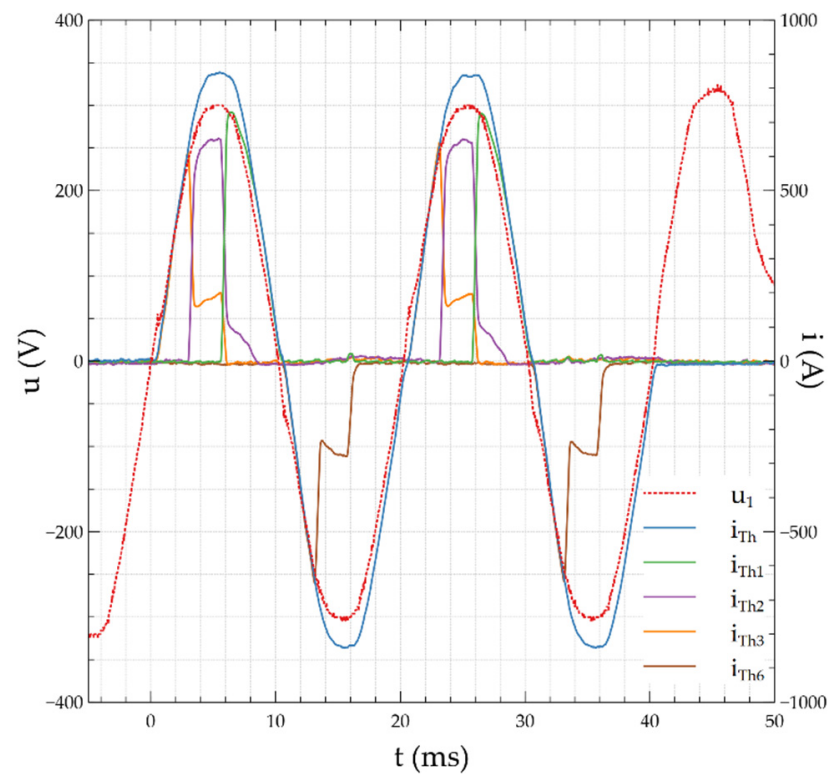

Figure 9. Current and voltage waveforms in a three-sectional MSAE system.

After a time of about $3 \mathrm{~ms}$ from the moment of detection of a simulated arc flash, a gating impulse is given to the $T_{h 2}$ section. Triggering the $T_{h 2}$ branch causes the $I_{T h 2}$ current to flow. The expected state is to turn off the $T_{h 3}$ section and current flow in the $T_{h 2}$ section branch. Research has shown that with the applied type of thyristors for currents exceeding several hundred amps, current absorption by the lower order branch (section) is usually only partial. This is evident in the form of the characteristic current drop $I_{T h 3}$ shown in Figure 9. An analogous situation occurs in $6 \mathrm{~ms}$ from the moment of simulated arc detection. Section $T_{h 1}$ is triggered by a triggering gating impulse. Triggering the $T_{h 1}$ branch causes $I_{T h 1}$ to flow. The voltage drop on a single conductive thyristor from the $T_{h 1}$ section is not sufficient to support the flow of current $I_{T h 3}$ in the $T_{h 3}$ branch, but it is sufficient to maintain the flow of $I_{T h 2}$ current through the $\mathrm{T}_{\mathrm{h} 2}$ branch. The process of control and current flow for a negative half-wave is identical to that described above, with the $\mathrm{T}_{\mathrm{h} 6}, \mathrm{~T}_{\mathrm{h} 5}$ and $\mathrm{T}_{\mathrm{h} 4}$ sections successively conducting the currents $\mathrm{T}_{\mathrm{h} 6}, \mathrm{~T}_{\mathrm{h} 5}$ and $\mathrm{T}_{\mathrm{h} 4}$. The $I_{T h}$ current flow recorded by the current probe and shown in Figure 9 is the sum of currents flowing in subsequent sections of the arc eliminator. The continuity of the $I_{T h}$ current flow shown in Figure 9 indicates the continuous, effective operation of the arc eliminator. 


\section{Influence of Thyristor Conduction Voltage Values on Arc Eliminator Operation}

The voltage-current characteristics in the conduction state of the TR51-40 and T00-150 [30,33] thyristors used in the- experiments described above are presented in Figure 10. With the increase in the value of forward current $I_{T}$, the value of the voltage drop $U_{T}$ increases. Exponential curve shape causes a rapid increase in voltage $U_{T}$ to a value of about $7 \mathrm{~V}$ at $I_{T S M}$ limit currents with an effective value of about 1000 A. As described in Section 4 and shown in Figure 9, during current flow close to the limit values, the thyristors of the higher section are not completely switched off due to the large voltage drop at the lower order MSAE section. The solution to this problem may be to increase the required forward voltage of the higher order sections or to reduce the voltage drop of the lower order sections. The schematic diagram presented in Figure 6 and waveforms recorded in this system (Figure 8) show a situation where, during current conduction, voltage on one thyristor of the lower order section is not able to maintain the conduction of the higher order section built of a larger number of semiconductors connected in series (three thyristors in series). At the moment of taking over the conductivity by the lower bypass branch section there is practically an immediate loss of current in the higher order section. Because this solution is quite expensive and involves the need to increase the number of serially connected semiconductor elements, Figure 11 shows a schematic diagram of an arc eliminator with a semiconductor element with a lower conduction voltage than the thyristor voltage in the higher order section. In sections $T_{h 2}, T_{h 1}$ and $T_{h 5}$, the TR51-40 thyristors are used, whereas in section $\mathrm{T}_{\mathrm{h}}$ the T00-150 thyristor is used. At the limit currents of the TR51-40 thyristor the voltage drop is over $7 \mathrm{~V}$, while for the same value of the flowing current on the T00-150 thyristor the voltage is about $2.4 \mathrm{~V}$. Such a low voltage at the thyristor terminals in the higher order section causes thyristors to practically cease to conduct or the current value will be slightly above single amperes.

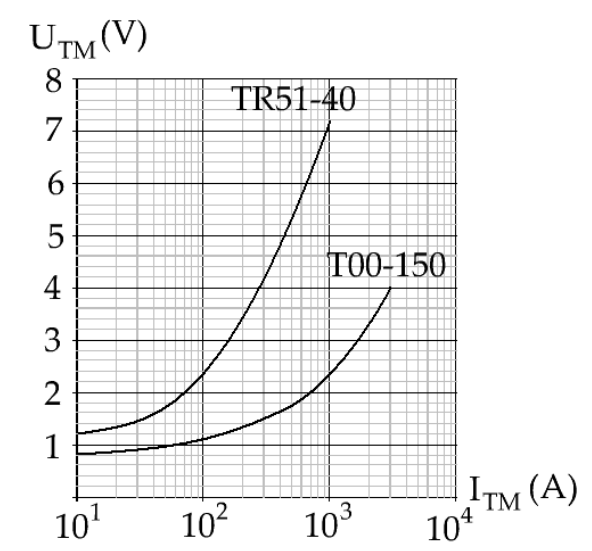

Figure 10. The voltage-current characteristics in conduction state for thyristors TR51-40 and T00-150-40.

Figure 11 shows a two-sectional arc eliminator in which sections $\mathrm{T}_{\mathrm{h} 2}, \mathrm{~T}_{\mathrm{h} 1}$ and $\mathrm{T}_{\mathrm{h} 5}$ were built using TR51-40 thyristors, while section $\mathrm{T}_{\mathrm{h} 4}$ was formed by T00-150 thyristor. The recorded waveforms of currents and voltages in this system for two maximum current values at $850 \mathrm{~A}$ and $1650 \mathrm{~A}$ are shown in Figure 12. For a positive half-wave, supply voltage may be conducted by the $T_{h 2}$ section, in which thyristors TR51-40 are used. At the moment when the current reaches a maximum of $850 \mathrm{~A}\left(I_{T h 2}=\right.$ $600 \mathrm{~A}$ effective current value), the $\mathrm{T}_{\mathrm{h} 1}$ section is triggered. The voltage on one conductive thyristor TR51-40 read from Figure 10 at current $I_{T M}=850 \mathrm{~A}$ is just over $6 \mathrm{~V}$.

For bypass branches of a higher order $\left(\mathrm{T}_{\mathrm{h} 2}\right)$ the voltage is distributed approximately halfway per each thyristor. From the characteristics in Figure 10 it can be read that for such a voltage value effective current of over 150 A can flow through this branch. In Figure 12a, this can be seen in the form of a sharp reduction in the instantaneous flowing current $I_{T h 2}$ from the maximum value of $850 \mathrm{~A}$ to about $200 \mathrm{~A}$. For the negative half-wave of the flowing current, conduction is taken over by the $\mathrm{T}_{\mathrm{h} 5}$ section built on the basis of TR51-40 thyristors. In the voltage amplitude, the $\mathrm{T}_{\mathrm{h} 4}$ section built of thyristor T00-150 is triggered. For the value of flowing current $I_{T 5}=600 \mathrm{~A}$ ( $850 \mathrm{~A}$ of maximum value) the voltage 
on the conductive thyristor T00-150 is about $2.2 \mathrm{~V}$. For a bypass branch of a higher order $\left(\mathrm{T}_{\mathrm{h}}\right)$ this voltage is distributed approximately halfway per each thyristor. From the characteristics in Figure 10 it can be read that for a voltage of $2.2 \mathrm{~V}$, thyristors can conduct current with the value of single amperes. In Figure 12a, this can be seen in the form of a total $I_{T h 4}$ current decay with a continuous flow of current $I_{T h}$ through the AE. In the system presented in Figure 11, the application of semiconductors of equal voltage drop in the direction of conduction $\left(T_{h 2}, T_{h 1}\right)$ and of semiconductors of different voltage drop for the negative voltage semi-wave $\left(T_{h 5}, T_{h 4}\right)$ was a purposeful procedure. The differences in the operation of each shunt module are clearly seen in current characteristics shown in Figure 12. It can be observed in them how much lower the current flowing through the higher-order section is when the lower-order branch begins to conduct.

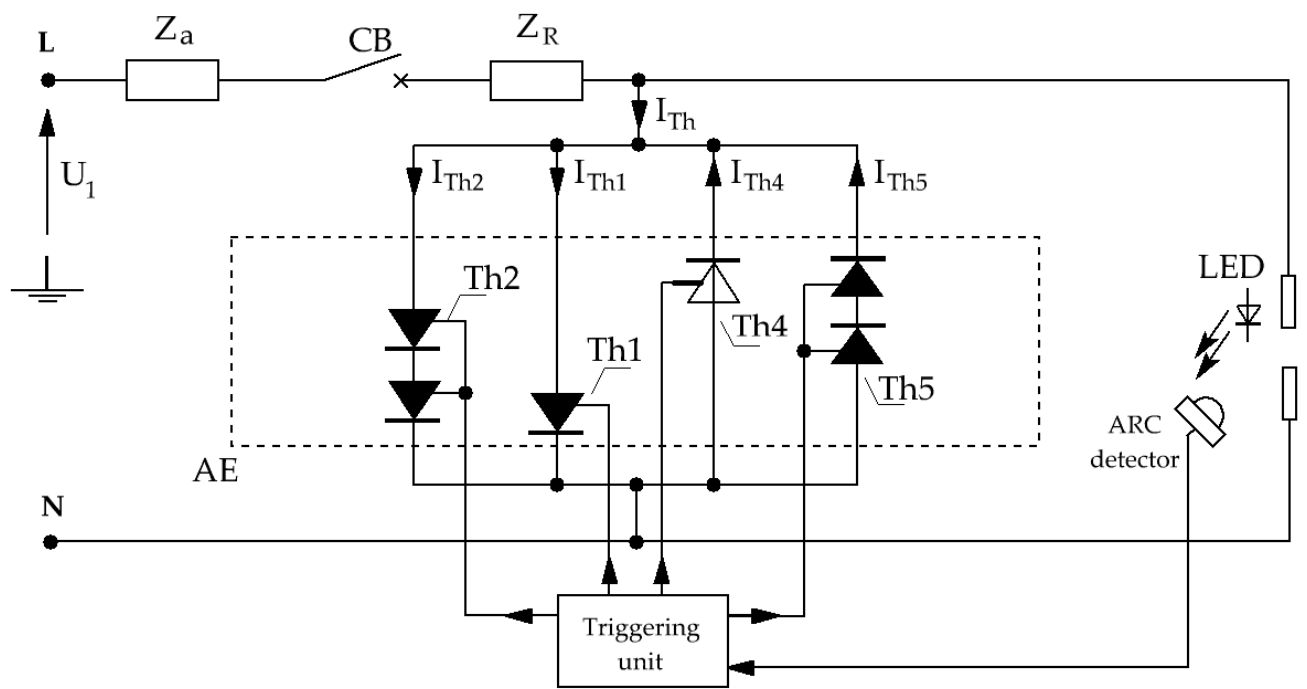

Figure 11. MSAE schematic diagram in a two-sectional system with $\mathrm{T}_{\mathrm{h} 4}$ semiconductor with a smaller voltage drop in the direction of forwarding.

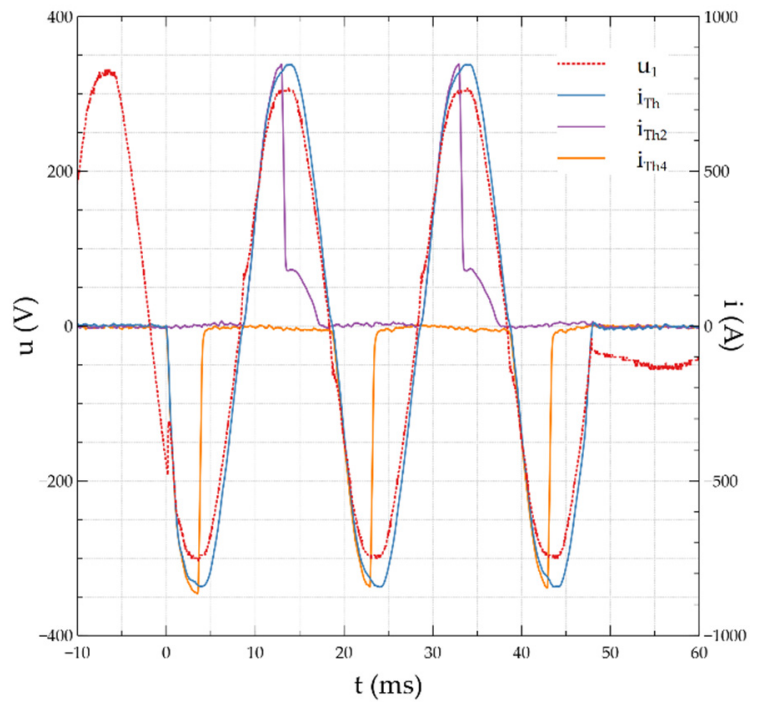

(a)

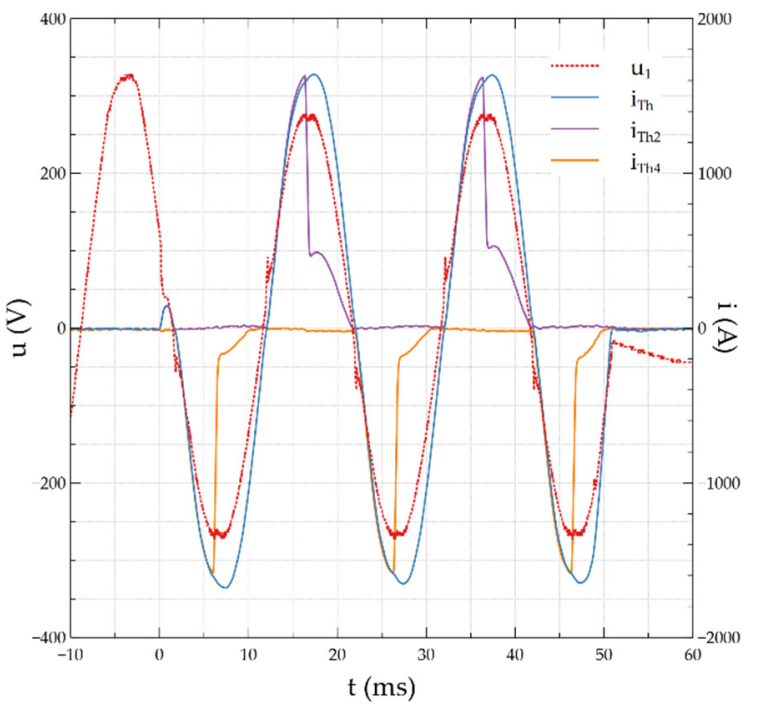

(b)

Figure 12. MSAE schematic diagram in a two-sectional system with $\mathrm{T}_{\mathrm{h} 4}$ semiconductor with a smaller voltage drop in the direction of forwarding: (a) $I_{T h \max }=850 \mathrm{~A},(\mathbf{b}) I_{T h \max }=1650 \mathrm{~A}$.

Figure $12 \mathrm{~b}$ shows the waveforms at higher peak current. The current amplitude in this case was limited by $Z_{R}$ impedance to about $1650 \mathrm{~A}$. Voltage drop in the direction of conduction for thyristor TR51-40 is more than $7.2 \mathrm{~V}$, which despite the operation of $\mathrm{T}_{\mathrm{h} 1}$ allows the current to flow through the 
section of higher order (of the same type of thyristors) with the value of more than $500 \mathrm{~A}$. In Figure $12 \mathrm{~b}$ this can be seen in the form of a large value of the "stair" of $I_{T h 2}$ current. For the thyristor T00-150 with a current flow of $1600 / \sqrt{ } 2$, the voltage drop across the semiconductor is $2.5 \mathrm{~V}$. This voltage will cause a current of the order of $30 \mathrm{~A}$ to flow through the higher order branch built on basis of thyristors TR51-40.

The values of voltage drops in the above considerations are read from the voltage and current characteristics of a given thyristor based on the measured value of the current flowing through the AE. The values of currents quoted above for the readout of voltage drop in the direction of conductivity are much smaller than those recorded in the real circuit in Figure 11 and presented in Figure 12. The actual voltage drops on conductive semiconductor sections are larger. This is due to the additional series impedance in the semiconductor circuit. Its value is influenced by:

- wires connecting specific semiconductor sections,

- connections to semiconductor terminals,

- different distances of individual semiconductor sections from the power source.

\section{Multi-Section Arc Eliminator in Real Arc Tests}

Figure 3 shows a three-sectional AE working with positive and negative voltage polarity. Detection of arc disturbance in the positive half-wave of the flowing current triggers sections $\mathrm{T}_{h 3}, \mathrm{~T}_{\mathrm{h} 2}$, and $\mathrm{T}_{\mathrm{h} 1}$, while sections $T_{h 6}, T_{h 5}$ and $T_{h 4}$ are triggered when the fault in the negative half-wave occurs. In the presented experiment, thyristors TR51-40 were used with a maximum average forward current of $40 \mathrm{~A}$ and a unique peak conduction current of $900 \mathrm{~A}$ [31]. The current amplitude was limited to $1600 \mathrm{~A}$ due to available test values. The source of the arc are two cylindrical carbon electrodes facing each other with a diameter $\phi$ equal to $5.76 \mathrm{~mm}$ spaced $1 \mathrm{~mm}$ apart. A fuse element was placed between the electrodes, which initiates ignition of the electric arc after a pre-selected time delay (resulting from the diameter of the fuse element). For safety reasons, the arc generation system (electrodes with a fuse element and flash detector) was enclosed in an insulated enclosure equipped with openings to limit the pressure increase inside the enclosure. The presented experiment corresponds to a short-circuit occurring close to the arc elimination system $\left(Z_{R}\right.$ control impedance practically negligible).

Figure 13a,b show the waveforms of:

- the supply current $i_{1}$,

- the current in the arc branch $i_{a}$,

- the current in subsequent conductive sections $i_{T h 3}, i_{T h 2}$ and $i_{T h 1}$,

- the total value of supply current $i_{T h}=i_{T h 3}+i_{T h 2}+i_{T h 1}$,

- the voltage measured at the electrodes of the arc source $u_{a}$.

The recorded arc interference occurred during the positive half-wave of the flowing current. In order to facilitate the readings, the moment $t=0 \mathrm{~s}$ was assumed at the moment of arc ignition. When the current flow exceeds the permissible value for a fuse element, the arc ignition occurs between the carbon electrodes after approx. $1.5 \mathrm{~ms}$. The arc voltage reaches the value of approx. $5.5 \mathrm{~V}$ at the moment of ignition.

When the electric arc ignites, the current drawn by the load from the power source is $i_{1}=1200 \mathrm{~A}$. The voltage on the resulting arc increases to a value of $u_{a}=115 \mathrm{~V}$. When the detector detects an explosion of a fusible element, a thyristor section consisting of three serially connected thyristors is triggered.

For the system in Figure 3 , this is the $\mathrm{T}_{\mathrm{h} 3}$ branch. Voltage $u_{2}$ is reduced to $32 \mathrm{~V}$. This is the voltage on three serially connected semiconductor elements of the arc eliminator. The commutation of current by the $\mathrm{T}_{\mathrm{h} 3}$ thyristor branch does not cause a decrease in arc voltage $u_{a}$ below the minimum arc burning value. A burning electric arc maintains current flow through the affected branch. The value of current $i_{a}$ is $120 \mathrm{~A}$ in the initial phase and increases to $200 \mathrm{~A}$ with an increasing value of the supply voltage. After the programmed trigger time of the subsequent thyristor sections has elapsed, 
the lower-third order branch, $\mathrm{T}_{\mathrm{h} 2}$, consisting of two serially connected thyristors, is switched on. The flow of the $i_{T h 2}$ current through the $\mathrm{T}_{\mathrm{h} 2}$ branch lowers the arc voltage below the minimum value of the arc burning, which results in its extinguishing and reducing the $i_{a}$ current to zero. In the last step, after the programmed time has elapsed, the branch of the lowest order $\mathrm{T}_{\mathrm{h} 3}$ built of one thyristor is switched on. Full commutation of the $i_{T h 3}$ current and a low voltage drop on the thyristor in the direction of conduction cause the complete switching off of $\mathrm{T}_{\mathrm{h} 3}, \mathrm{~T}_{\mathrm{h} 2}$ and $i_{T h 3}, i_{T h 2}$ branches and the disappearance of $i_{T h 3}$ and $i_{T h 2}$ currents. In this case, the arc was already extinguished during the work of the second section $\left(\mathrm{T}_{\mathrm{h} 2}\right)$ of the MSAE.

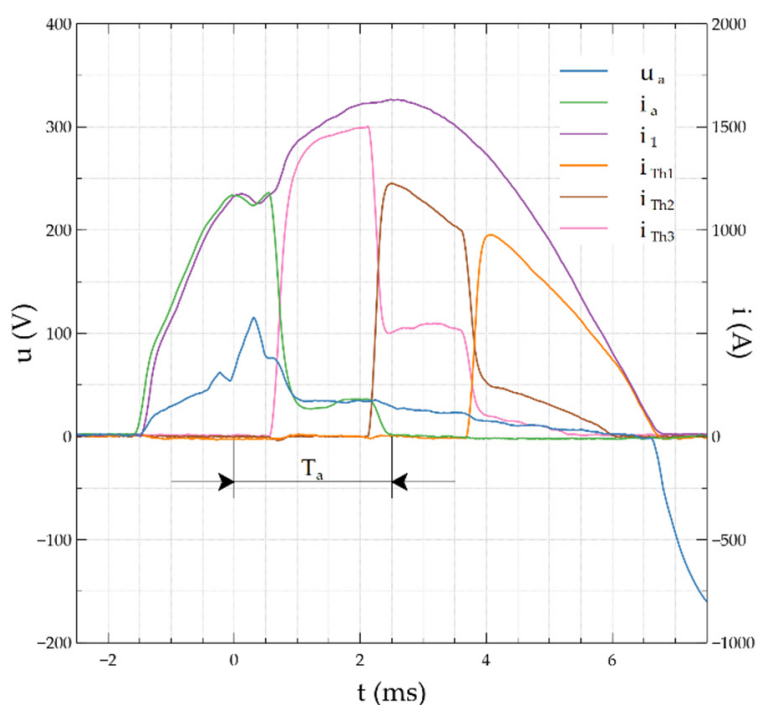

(a)

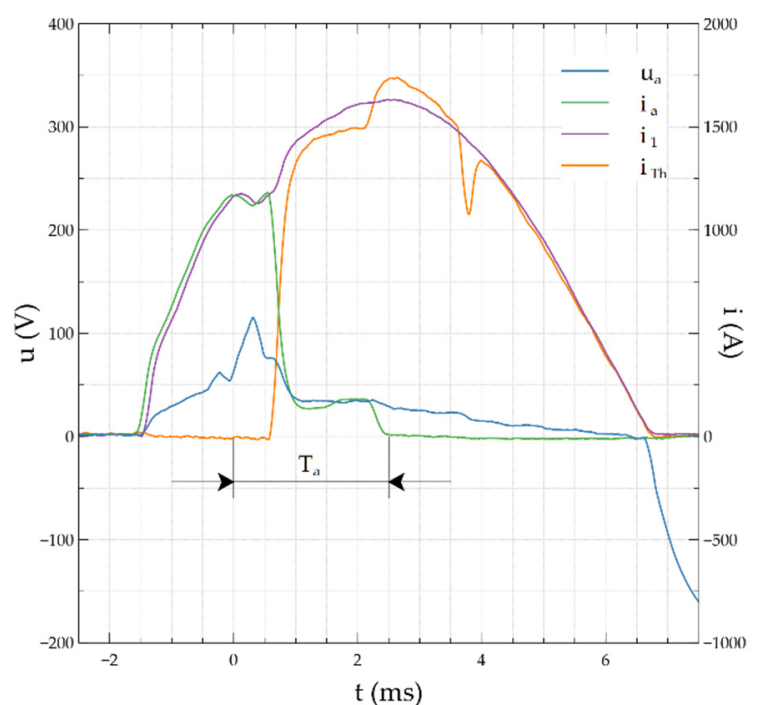

(b)

Figure 13. Waveforms of current and voltage of the arc in a circuit protected by the MSAE system: (a) partial currents; (b) current waveforms with the sum of $I_{T h}$.

Arc time $T_{a}$ measured from the detection of the electric arc to the acquisition of full conduction by AE thyristor branches is $2.5 \mathrm{~ms}$. The arc extinguishing time results from the delay in the detection of the electric arc and the delay in triggering the lower order bypass section. The voltage on the conductive thyristor branch $\mathrm{T}_{\mathrm{h} 3}$ is sufficient to sustain the free burning of an electric arc. This time can be shortened by triggering the lower order branch faster or by using semiconductor devices with a lower voltage drop in the direction of conductivity so that it is less than the voltage of the burning arc. Although it was shown in paper [15] that the time of extinguishing the electric arc in the AE built in the system of single oppositely connected thyristors is about $0.7 \mathrm{~ms}$ for the resistive load, the single-stage eliminator is characterized by a much lower current load capacity. It should also be emphasized that despite the extension of the arc burning time and the flow of arc current through the place affected by the fault, the value of current $i_{a}$ decreased six times compared to the value at the time of the arc fault. This means that the effects of the arc burning are significantly reduced. Figure $13 \mathrm{~b}$ shows the summed-up values of the currents of the individual MSAE bypass branches.

Figure 14 shows the situation in which arc detection triggers MSAE operation. From now on, the MSAE operation has been programmed as switched off. In the area affected by the failure, the arc is extinguished after $T_{a}=2.8 \mathrm{~ms}$. Favorable thermal conditions and a short distance between the electrodes (arc generator) cause reignition of the discharge between the measuring electrodes. The arc ignites again for a negative half-wave of the supply voltage. The current in the arc branch starts increasing rapidly to a peak of $1250 \mathrm{~A}$. This experiment was presented deliberately to illustrate MSAE effectiveness and the effects of its inaction. The state-of-the-art solution shown, for example, in [14] may, due to the limit parameters of the thyristors, reduce the possibility of the thyristors reacting again for the next half-waves of the flowing current. The solution in Figure 3, for the same values of the interfering current and the use of identical thyristors as in work [15], allows the time of operation of the 
arc eliminator to be three times longer. However, if the operating time is limited to one half-wave (as described above), the use of a 3-sectional shunting thyristor branch allows to increase the eliminated disturbing current $\sqrt{ } 3$ times while maintaining the required thermal parameters of the elements used.

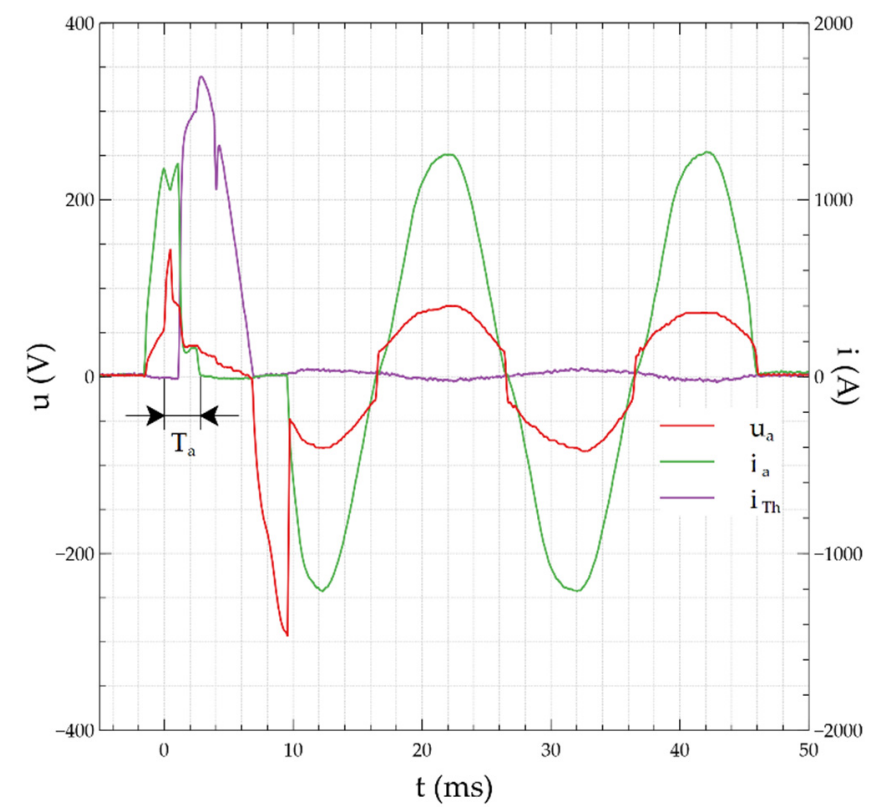

Figure 14. Current and voltage waveforms in the MSAE circuit with intentionally blocked operation in the second half-wave of the supply voltage.

Figure 15 shows the arc eliminator in a two-sectional solution. The purposefulness of using this solution with the multiplied number of elements of the higher order section is described in Section 4 . Figure 16 shows the oscillograms of current and voltage recorded in the experimental circuit during arc fault.

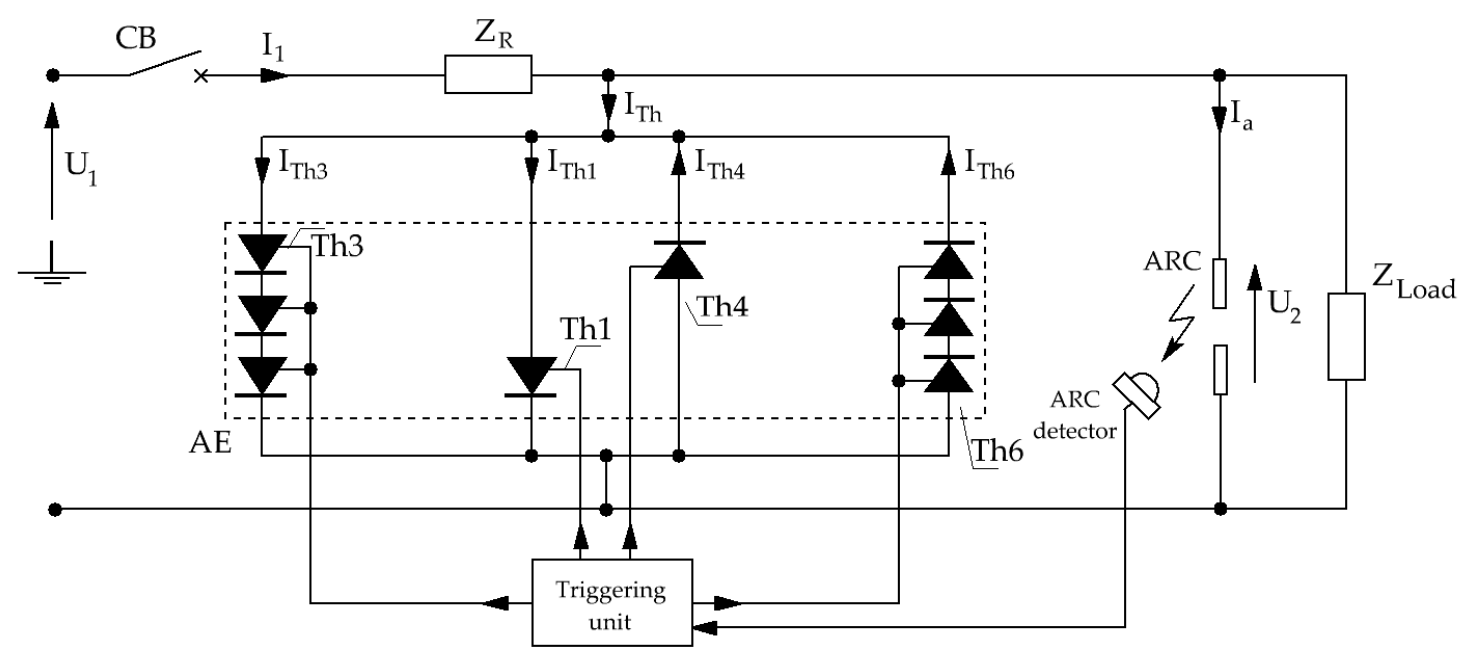

Figure 15. Circuit diagram of a test circuit with a two-sectional arc eliminator.

At $t=0 \mathrm{~s}$, the voltage at the arc source terminals increases rapidly due to fuse element explosion. A triggered arc detector sends a thyristor trigger pulse. After approximately $0.7 \mathrm{~ms}$, conduction of the first semiconductor section of the arc eliminator begins. The thyristor semiconductor branch $\mathrm{T}_{\mathrm{h} 6}$ commutates the current flow from the branch affected by the arc. The current in the arc branch decreases its value from $1200 \mathrm{~A}$ to $70 \mathrm{~A}$. The voltage with the voltage drop value of the conductive $\mathrm{T}_{\mathrm{h} 6}$ thyristors sustains the burning electric arc, while the energy emitted on the arc decreases in such a 
ratio as the value of current $i_{a}$. Tripping of the $T_{\mathrm{h} 4}$ branch causes the total commutation of current from the $T_{\mathrm{h} 6}$ branch and the affected branch. The electric arc goes out and the measured time $T_{a}$ is $3.5 \mathrm{~ms}$.

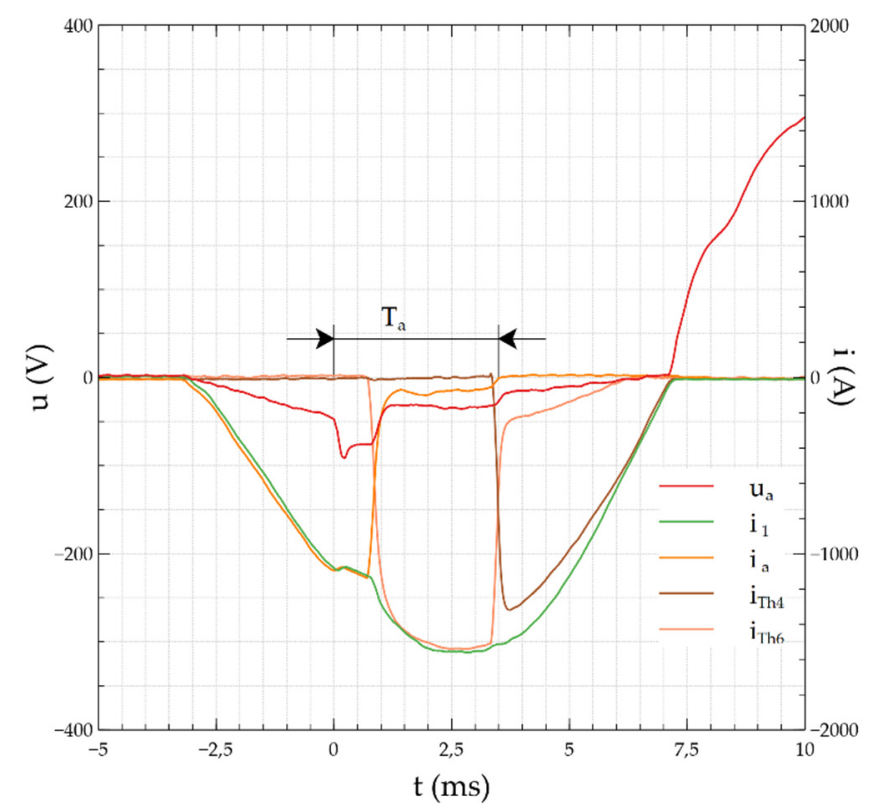

Figure 16. Current and voltage waveforms in a two-sectional arc eliminator system.

Figure 17 is a diagram of a two-sectional arc eliminator. In branches $T_{h 3}, T_{h 1}$ and $T_{h 6}, T R 51-40$ thyristors are used, and in $\mathrm{T}_{\mathrm{h} 4}$, thyristor T00-150 is applied, one with lower voltage drop in the direction of conduction. Such a solution, similarly to the system in Figure 15, allows to compare the efficiency of thyristor eliminators made of elements with different operating characteristics.

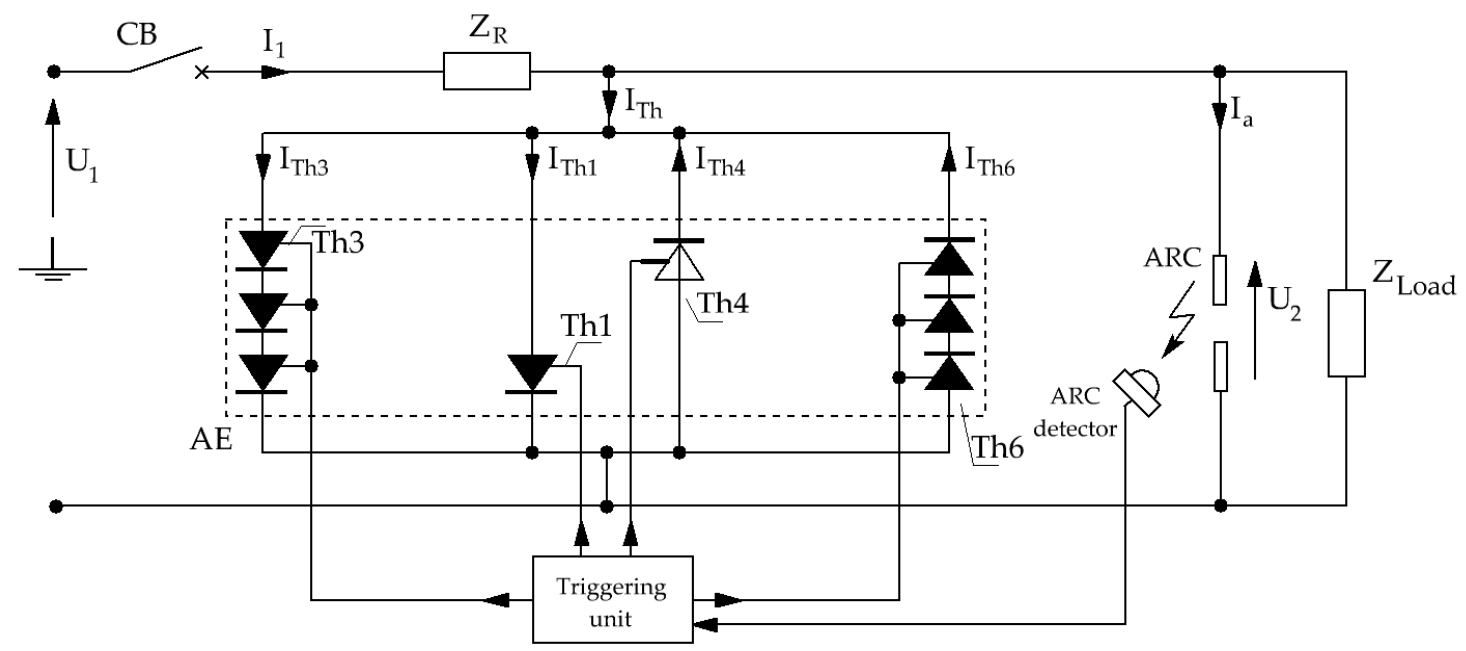

Figure 17. Schematic diagram of a two-sectional arc eliminator containing one of the thyristors with a smaller voltage drop in conduction direction $\mathrm{T}_{\mathrm{h} 4}$.

Oscillograms of current and voltage waveforms recorded in the system presented in Figure 17 are shown in Figure 18. After the detector detects a disturbance, the first $\mathrm{T}_{\mathrm{h} 3}$ semiconductor section is triggered and the $i_{T h 3}$ current flow appears. After the set time is over, the lower order section $\mathrm{T}_{\mathrm{h} 1}$ and the current flow $i_{T h 1}$ are triggered. However, the arc is still not extinguished. Favorable thermal conditions and a short distance of the carbon electrodes cause another ignition of the arc in the negative half-wave of the supply voltage. The $\mathrm{T}_{\mathrm{h} 6}$ thyristor section and $i_{T h 6}$ current flow is switched on and, after a given time, conduction and $i_{T h 1}$ current flow is taken over by the lower order $T_{h 1}$. In the $T_{h 1}$ 
section, there is a thyristor with a smaller voltage drop in the direction of conduction, hence the faster shutdown of the higher order section and current loss in this section. The waveform $u_{a}$ in the first part of the positive half-wave of the supply voltage illustrates the waveform recorded at the arc source terminals. Before ignition of the arc, it is the voltage on the conductive fuse element, while at the moment of ignition, the oscillogram shows the voltage on the arc. At the moment of triggering the first semiconductor section $\mathrm{T}_{\mathrm{h} 1}$, the current in the branch of the arc $i_{a}$ suddenly drops to zero, so it can be concluded that the arc is extinguishing. From this moment on, the recorded curve of the $u_{a}$ shows the voltage course on the thyristor sections of the AE.

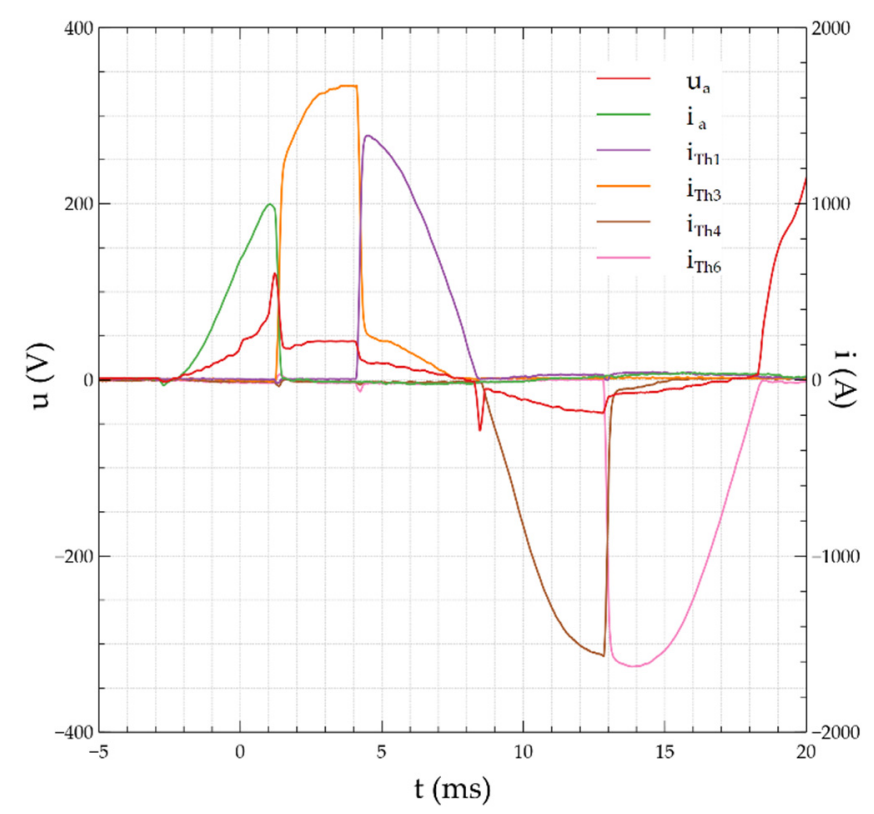

Figure 18. Current and voltage waveforms in a two-sectional arc eliminator system containing one of the thyristors with a smaller voltage drop in conduction direction.

\section{Conclusions}

After carrying out a number of studies and experiments presented in this paper, it can be concluded:

- there is a possibility of effective extinguishing of the arc fault in any semi-wave of current flow with the use of MSAE,

- the semiconductor bypassing systems enable very fast (faster than mechanical short-circuiting switches) bypassing of an electric circuit affected by arc fault, aiming at creating an alternative, privileged way for the flow of current. The result is a very fast elimination of electric arc and shortening of the fault current flow,

- there is a significant dependence of the effective (total) arc quenching on the selection of thyristor performance parameters. It is preferred that the thyristors in the lower (and particularly the lowest) branch have the lowest possible forward voltage. If this condition is not met, the eliminator system often works less efficiently. However, in each case, there is at least a reduction in the value of the arc current and the energy it emits,

- the MSAE system makes it possible to increase the current-carrying capacity of individual arc eliminator sections, and consequently to increase the permissible total current $\mathrm{AE}$. The sequential division of the interference current into individual semiconductor branches enables the conduction of fault currents that are much larger than the allowable conduction currents of a single thyristor, usually given in catalogs for a conduction time of $10 \mathrm{~ms}$,

- $\quad$ sequential (in each of the half-waves) switching on of current by individual bypass branches enables, admittedly, a significant increase in the current-carrying capacity of the arc eliminator, 
yet it can cause an extension of the arc time. This voltage value may preclude the arc fault from extinguishing immediately. Despite the burning arc, the shunt semiconductor branch takes over much of the current from the branch affected by the arc. The value of the arc current is initially significantly reduced, and when the next semiconductor branch is activated, the arc extinguishes completely,

- through proper control of thyristor triggering impulses and their conduction time, it is possible to optimize the energy load degree of individual thyristors,

- the design and appropriate programming of MSAE enables the device to be used in circuits equipped with a short-circuiting switch with adjustable response times.

Author Contributions: Section 1 was prepared by K.N. and G.D. Section 2 was described by K.N. and J.J. Section 3 was prepared by all the authors. Sections 4-6 were prepared by K.N. and J.J. Conclusions (Section 7) were prepared jointly by all the authors. All authors have read and agreed to the published version of the manuscript.

Funding: This research was funded by the Polish Ministry of Science and Higher Education, grant number 04/41/SBAD/4408.

Conflicts of Interest: The authors declare no conflict of interest.

\section{References}

1. Berczynski, R.; Kulas, S.J. Analysis of the movement dynamics of contacts and contact-set of the making switches. Prz. Elektrotech. 2017, 93, 16-20. (In Polish)

2. Boren, S.G. Intelligence Automatic Bypass for a Motor Control Device Fault. US Patent No. US20040252423A1, 16 December 2004.

3. Bhargava, B.; Haas, R.G. Thyristor protected series capacitors project at Southern California Edison Co. In Proceedings of the IEEE Power Engineering Society Summer Meeting (PESS), Chicago, IL, USA, 21-25 July 2002; pp. 241-246.

4. Pulvirenti, F.; La Scala, A.; Pennisi, S. Low voltage-drop bypass switch for photovoltaic applications. In Proceeding of the IEEE International Symposium on Circuits and Systems (ISCAS), Seoul, South Korea, 20-23 May 2012; pp. 2283-2286.

5. Backman, M.; Demetriades, G.; Shukla, A. Hybrid Circuit Breaker. Patent No. EP2465129B1, 24 April 2013.

6. Liu, L.; Zhuang, C.; Wang, Z.; Jiang, Z.; Wu, J.; Chen, B. A hybrid DC vacuum circuit breaker for medium voltage: principle and first measurements. IEEE Trans. Power Deliv. 2015, 30, 2096-2101. [CrossRef]

7. Naidu, M.; Schoepf, T.J.; Gopalakrishnan, S. Arc fault detection scheme for 42-V automotive DS networks using current shunt. IEEE Trans. Power Electr. 2006, 21, 633-639. [CrossRef]

8. New Circuit Breakers Prevent Electrical Fires. Available online: https://phys.org/news/2012-10circuit-breakers-electrical.html?utm_source=TrendMD\&utm_medium $=$ cpc\&utm_campaign=Phys.org_ TrendMD_1 (accessed on 10 November 2019).

9. Hatsagi, B. Electromagnetic Modelling and Testing of a Thomson Coil Based Actuator. Master's Thesis, KTH Royal Institute of Technology, Stockholm, Sweden, 2017.

10. Pei, X.; Smith, A.C.; Shuttleworth, R.; Vilchis-Rodriguez, D.S.; Barnes, M. Fast operating moving coil actuator for vacuum interrupter. IEEE Trans. Energy Convers. 2017, 32, 931-940. [CrossRef]

11. Kay, J.A.; Kumpulainen, L. Maximizing protection by minimizing arcing times in medium-voltage systems. IEEE Trans. Ind. Appl. 2013, 49, 1920-1927. [CrossRef]

12. Bissal, A.; Eriksson, A.; Magnusson, J.; Engdahl, G. Hybrid multi-physics modeling of an ultra-fast electro-mechanical actuator. Actuators 2015, 4, 314-335. [CrossRef]

13. Tirmizi, A.A. Pyrotechnic Circuit Breaker. Patent No. US7239225B2, 3 July 2007.

14. UFESTM Ultra-Fast Earthing Switch. Available online: https://new.abb.com/medium-voltage/apparatus/arcfault-protection/ultra-fast-earthing-switch-ufes (accessed on 20 November 2019).

15. Nowak, K.; Janiszewski, J.; Dombek, G. Thyristor arc eliminator for protection of low voltage electrical equipment. Energies 2019, 12, 2749. [CrossRef]

16. Zhang, Z.; Ma, B.; Friberg, A. Thyristor working as arc eliminator protecting electrical apparatus in low voltage power system. In Proceedings of the IEEE International Conference on Industrial Technology (ICIT), Seville, Spain, 17-19 March 2015; pp. 1216-1219. 
17. Kazmierczak, M. Arc faults - operational experience in Polish professional and industrial power engineering. Autom. Elektroenerg. 2011, 2, 98-109. (In Polish)

18. Volger, J. Arc fault protection as seen by employers' liability insurance associations. In The Arc-Fault Demonstration in the Head Office of the Moeller; GmbH: Bonn, Germany, 2008.

19. Hussain, G.A. Method for Arc-Flash Protection in Medium Voltage and Low Voltage Switchgear. Ph.D. Thesis, Aalto University, Helsinki, Finland, 2015.

20. Dugan, T. Reducing the flash hazard. IEEE Ind. Appl. Mag. 2007, 13, 51-58. [CrossRef]

21. Rojek, A.; Skrzyniarz, M. Contact arc time-Important parameter of DC high-speed circuit-breakers. In Proceedings of the International Scientific and Practical Conference Energy-Optimal Technologies, Logistic and Safety on Transport (EOT), Lviv, Ukraine, 19-20 September 2019; pp. 1-7.

22. Guo, X.; Cui, X.; Qi, L.; Cai, L.; Yang, Z. Bridge Arm Bypass Protection Circuit of Modularization Multi-Level Converter Aiming at Direct Current Short Circuit Fault. Patent No. CN106602531 (A), 26 April 2017.

23. Garzon, R.D. Arcing Fault Protection System for a Switchgear Enclosure. Patent No. US006141192A, 31 October 2000.

24. Nowak, K.; Janiszewski, J. Hybrid Short-Sircuiting Switch. Patent application No. P.427947, 2018.

25. Nowak, K.; Janiszewski, J. Hybrid Short-Circuiting Switch. Patent application No. P.427948, 2018.

26. Wettengel, S.; Lindenmueller, L.; Laessig, F.; Bernet, S.; Stelte, M.; Drilling, C.; Leifeld, M.; Schiele, J.; Schenk, M. Rectifier design for frequency converters using thyristor or diode modules in parallel connection, Intelligent Motion, Renewable Energy and Energy Management. In Proceedings of the International Exhibition and Conference for Power Electronics, Intelligent Motion, Renewable Energy and Energy Management (PCIM), Shanghai, China, 26-28 June 2012; pp. 79-85.

27. SCR in Parallel. Available online: https://www.daenotes.com/electronics/industrial-electronics/SCR-parallelconnection-operation (accessed on 8 January 2020).

28. Thyristor Theory and Design Considerations. Handbook, 1st ed.; ON Semiconductor: Phoenix, AZ, USA, 2005; pp. 10-25.

29. TME Electronic Components. Available online: https://www.tme.eu/pl/katalog/tyrystory-pojedyncze_100181/ (accessed on 8 November 2019).

30. The Catalogue of Power Semiconductor Devices: Thyristors. Available online: http://delibra.bg.polsl.pl/ Content/30503/BCPS_34289_1986_Tyrystory---przyrzad.pdf (accessed on 3 July 2019).

31. Pawelski, W. Thyristor Control; Scientific and Technical Publishing House: Warsaw, Poland, 1974; pp. 77-86. (In Polish)

32. Nowak, K. Thyristor microprocessor controller. Pozn. Univ. Technol. Acad. J. Electr. Eng. 2018, 95, 77-86. (In Polish)

33. The New Catalogue of LAMINA Power Semiconductor. Available online: http://laminasi.com.pl/katalogi_ en.htm (accessed on 3 March 2019).

(C) 2020 by the authors. Licensee MDPI, Basel, Switzerland. This article is an open access article distributed under the terms and conditions of the Creative Commons Attribution (CC BY) license (http://creativecommons.org/licenses/by/4.0/). 